\title{
Helen Salisbury: Doctors' duties in a fractured welfare state
}

\author{
Helen Salisbury GP
}

Oxford

Like many other GPs around the country, I'm spending more and more time writing medical reports to appeal on behalf of patients who have been refused welfare benefit payments. Welfare is a right: we have a welfare state we all pay into through taxation, and we rely on it when we are sick or become unable to work. It's a mark of a humane society that we look after each other in this way.

The main grounds for refusing incapacity benefit is that the person has been found fit to work by someone at an outsourced assessment company. Many of my patients with severe physical or mental health difficulties spend weeks in a state of heightened anxiety before an assessment. I know that it takes some patients all of their energy and resolve to get up, dress, and make it to a GP appointment on time. Engaging in the world of paid work is simply not a realistic ambition for them, however much they'd love to. Unfortunately, their struggles may not be captured in the questions the assessment service uses on its form. ${ }^{1}$

At the assessment, patients have to discuss and demonstrate what they can and can't do. This is difficult, unpleasant, and undignified. Most people want to project the best version of themselves-one that's strong and capable, making the most of their abilities. A patient with learning difficulty may say that he can use public transport independently, omitting that he's safe to do this only if he's been taken on the same journey 15 times by his carer. Admitting to a stranger that you have problems controlling your bladder or bowels is deeply undignified. Some patients, determined not to be beaten by their disabilities, minimise the pain it causes them to walk 50 yards.

A negative ruling by the Work Capability Assessment body is often followed by months of desperation as we appeal the decision. In most cases (65\%, says the Department for Work and Pensions $)^{2}$ the original decision is overturned on appeal.
This all creates extra work for doctors: not just writing reports but also supporting patients with worsening mental health as a result of this punitive system. Suicides and antidepressant prescriptions have both been shown to rise in line with disability reassessments. ${ }^{3}$ Patients judged as no longer qualifying for support seek our help for their desperation and low mood, but cognitive behavioural therapy and antidepressants are a poor answer to a fractured welfare state. We're instructed by the General Medical Council, in its document Duties of a Doctor, to "take prompt action if you think that patient safety, dignity or comfort is being compromised."

My patients' safety, dignity, and comfort are indeed being compromised. It seems unlikely that reporting the DWP to the General Medical Council will be productive. However, as doctors we should use our collective voice to stand up for our patients and demand change to this deeply damaging system.

Competing interests: See www.bmj.com/about-bmj/freelance-contributors.

Provenance and peer review: Commissioned; not externally peer reviewed.

1 Department for Work and Pensions. Capability for work questionnaire. 13 Mar 2019. https: //www.gov.uk/government/publications/capability-for-work-questionnaire.

Department for Work and Pensions. Employment and support allowance: work capability assessments, mandatory reconsiderations and appeals. $14 \mathrm{Mar} 2019$. https://assets. publishing.service.gov.uk/government/uploads/system/uploads/attachment_data/file/ 785696/esa-wca-summary-march-2019.pdf.

3 Barr B, Taylor-Robinson D, Stuckler D, Loopstra R, Reeves A, Whitehead M. 'First, do no harm': are disability assessments associated with adverse trends in mental health? A longitudinal ecological study. J Epidemiol Community Health 2016;70:339-45. 10.1136/jech-2015-206209 26573235

4 General Medical Council. Good medical practice: the duties of a doctor registered with the General Medical Council. https://www.gmc-uk.org/ethical-guidance/ethical-guidancefor-doctors/good-medical-practice/duties-of-a-doctor.

Published by the BMJ Publishing Group Limited. For permission to use (where not already granted under a licence) please go to http://group.bmj.com/group/rights-licensing/ permissions 